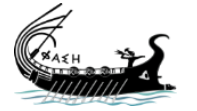

journal.phaselis.org
PHAS LLIS

Issue VI (2020)
Disiplinlerarası Akdeniz Araştırmaları Dergisi

Journal of Interdisciplinary Mediterranean Studies

\title{
Phaselis 2019 Yılı Arkeojeofizik Araştırmaları: Hellenistik Tapınak
}

\author{
Phaselis' Archaeogeophysical Research in 2019: \\ Hellenistic Temple
}

\author{
Fethi Ahmet YÜKSEL \\ (D) https://orcid.org/0000-0003-2207-1902
}

\section{Fikret BOŞÇA}

open 2 access journals

The entire contents of this journal, Phaselis: Journal of Interdisciplinary Mediterranean Studies, is open to users and it is an 'open access' journal. Users are able to read the full texts, to download, to copy, print and distribute without obtaining the permission of the editor and author(s). However, all references to the articles published in the e-journal Phaselis are to indicate through reference the source of the citation from this journal.

Phaselis: Journal of Interdisciplinary Mediterranean Studies is a peer-reviewed journal and the articles which have had their peer reviewing process completed will be published on the web-site (journal.phaselis.org) in the year of the journal's issue (e.g. Issue IV: JanuaryDecember 2018). At the end of December 2018 the year's issue is completed and Issue V: January-December 2019 will begin.

Responsibility for the articles published in this journal remains with the authors.

cc) (i) (2) This work is licensed under a Creative Commons Attribution-

cy No SA NonCommercial-ShareAlike 4.0 International License.

Citation F. A. Yüksel - F. Boşça, "Phaselis 2019 Yılı Arkeojeofizik Araştırmaları: Hellenistik Tapınak ". Phaselis VI (2020) 1-12. http://dx.doi.org/10.18367/Pha.20001

Received Date: 21.10.2019 | Acceptance Date: 14.02.2020

Online Publication Date: 06.04.2020

Editing

Phaselis Research Project

www.phaselis.org 


\title{
Phaselis 2019 Yılı Arkeojeofizik Araştırmaları: Hellenistik Tapınak
}

\author{
Phaselis' Archaeogeophysical Research in 2019: Hellenistic Temple
}

\author{
Fethi Ahmet YÜKSEL - Fikret BOŞÇA ${ }^{* *}$
}

\begin{abstract}
Öz: Kent tarihi araştırmaları ile alan yönetiminin sistemli ve sürdürülebilir kılınması amacıyla yeraltında gömülü kalmış arkeolojik malzemelerin, mimari elemanların ve yapı temellerinin yerlerinin belirlenmesi amacıyla arkeojeofizik çalışmalar yapılmaktadır. 1811 yılından itibaren, farklı amaç ve doğrultularda ilerleyerek kesintilerle 2000 yılına değin süregelen Phaselis araştırmalarında, Kent tarihi araştırmaları ile alan yönetiminin sistemli ve sürdürülebilir, iki temel unsur dikkate alınması önem kazanır ${ }^{1}$. Arkeojeofizik çalışmada Hellenistik Tapınak olduğu düşünülen alanda Elektrik Rezistivite Tomografi (ERT) yöntemi kullanılmıştır. Çalışmada $1 \mathrm{~m}$ profil aralı̆̆ı ve $1 \mathrm{~m}$ elektrot aralı̆̆ında ölçümler alınmıştır. Elektrik rezistivite ölçümlerin veri işlem aşamaları yapıldıktan sonra iki ve üç boyutlu görüntüleri oluşturulmuştur. Elde edilen ERT profil kesitleri ve iki boyutlu kat haritalarında, toprak altında kalmış mimari unsurlar ve yapı temellerine ait olabilecek, yüksek rezistiviteli anomali değerlerinin köşeli, kare, geometrik, dairesel ve çizgisel görünümlü geometrik formlar verdiği belirlenmiştir. Bu lokasyonlar arkeolojik açmalar ile denetlenmelidir.
\end{abstract}

Anahtar sözcükler: Phaselis, Arkeojeofizik, ERT, Yerleşim Arkeolojisi

Abstract: Archaeogeophysical research are carried out to determine the location of archaeological materials, architectural elements and building foundations buried underground in order to make the area management systematic and sustainable through urban history researches. In Phaselis researches, which continued from 1811 until 2000 with interruptions, advancing in different goals and directions, it is important to take into account the systematic and sustainable, two basic elements of urban management and field management. In the archaeogeophysical-based approach, the Electrical Resistivity Tomography (ERT) method was used in the area considered to be a Hellenisic Temple. In the study, measurements were taken in the range of $1 \mathrm{~m}$ profile and $1 \mathrm{~m}$ electrode. After the data processing stages of electrical resistivity measurements were made, two and three dimensional images were created. In the obtained ERT profile sections and two-dimensional floor maps, it was determined that the high resistivity anomaly values, which may belong to the underground architectural elements and building foundations, give angular, square, geometric, circular and linear geometric forms. These locations should be inspected by archaeological trenches.

Keywords: Phaselis, Archaeogeophysics, ERT, Settlement Archaeology

* Dr. Öğr. Üyesi, İstanbul Üniversitesi-Cerrahpaşa, Mühendislik Fakültesi, Jeofizik Müh. Bölümü, İstanbul. fethiahmety@gmail.com | o https://orcid.org/0000-0003-2207-1902

** Jeofizik Müh., ARZ Zemin Etüd Ve Mühendislik Hizmetleri, Antalya, fikretbosca@gmail.com

1 http://www.phaselis.org/phaselis-arastirmalari/kent-ve-akropolis-arastirmalari 
Phaselis, Antalya İli, Kemer İlçesi (Fig. 1, 2) sınırları içinde olup; Kemer ilçe merkezi Antalya'nın 43 $\mathrm{km}$ batısındadır. İıçe Batı Toros dağlarının eteklerinde $46 \mathrm{~km}$ uzunluğundaki kıyı şeridi üzerinde kurulmuştur. Doğusu Akdeniz, batısı orman ve dağlarla çevrili olan ilçenin yüzölçümü 53.483 $\mathrm{km}^{2 \prime}$ dir. İlçenin 45.000 hektarlık alanı ormandır. İlçenin iklimi yazları sıcak ve kurak, kışları ise ılık ve yağışııdır. İlçe merkezinin en yüksek rakımı ise $15 \mathrm{~m}^{\prime} \mathrm{dir}^{2}$.

Yılda ortalama 300 günü güneşli geçer. Deniz suyu sıcaklığı kış aylarında 10-12, yaz aylarında 27-29 @ C'dir. Bu rakamlar Kemer'de 8 ay denize girilebileceği anlamına gelmektedir.

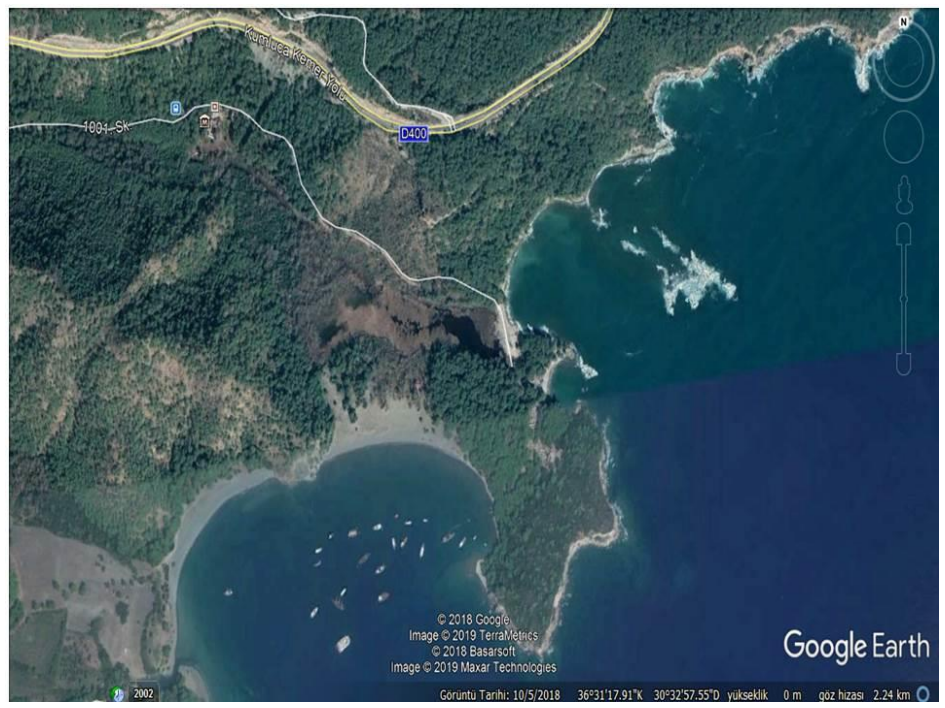

Fig. 1. Antalya Ili, Kemer İlçesi Phaselis Antik Kentinin uydu görünüşü, Google Earth

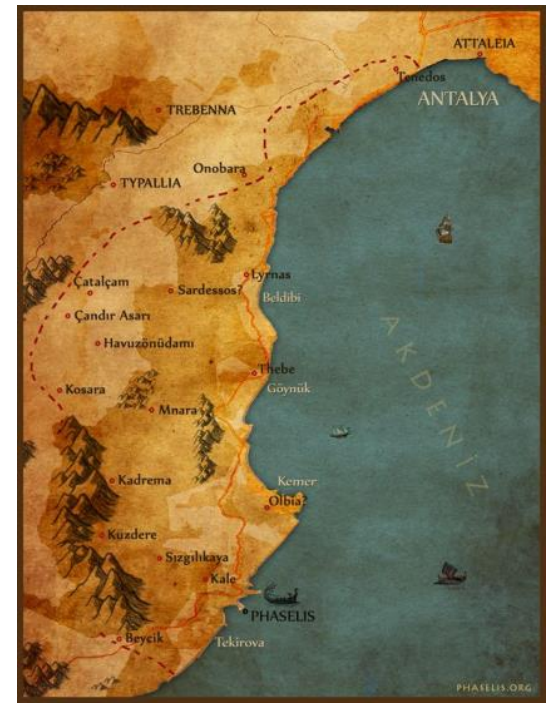

Fig. 2. Antalya ili, Kemer illçesi Phaselis Antik Kenti konumu (www.phaselis.org)

Kentin Akdeniz'e uzanan bir yarımada üzerinde MÖ VII. yüzyılda Rodoslu kolonistlerce kurulduğu söylecesi yaygındır. Coğrafi konumu Akdeniz dünyasının önemli bir liman kenti olduğunu gösterir. Biri yarımadanın kuzeyinde, diğeri kuzeydoğuda, üçüncüsü ise güneybatı kısmında yer alan üç limana sahiptir. Phaselis 1158'deki Selçuklu kuşatmasından sonra gerek depremler, gerekse Antalya ve Alanya limanlarının işlevlerinin artmasıyla önem kaybedip, 13. yüzyıl başlarında tamamen terk edilir. Günümüze çoğunlukla Roma ve Doğu Roma kalıntıları ulaşabilmiştir ki, bunlar kentin ana aksını oluşturan ve kuzey, güney limanlarını birleştiren ana caddenin (G) her iki yanında sıralanır. Pax Roma'na (Roma Barışı) ile MS I-II. yüzyıllar boyunca yeni bir yapılanma ve yönetim sürecine giren kenti 130 yılında Roma imparatoru Hadrianus tarafından ziyaret edilir.

Ana cadde agora ile tiyatro arasında genişleyerek küçük bir meydan oluşturur. Meydanın güneydoğu köşesindeki basamaklar tiyatro ve akropolis'e ulaşımı sağlar. Phaselis tiyatrosu akropolisin yamacına inşa edilmiş küçük boyutlu tipik bir Hellenistik Dönem tiyatrosudur. Çokluk bölgenin doğal taşı konglomera bloklarından inşa edilmiş olup sahne binasının Roma Dönemi'nde eklendiği, Doğu Roma Dönemi'nde ise kısmen şehri koruyan yeni surların bir parçası olduğu kalıntılardan anlaşımaktadır.

Kent tarihi araştırmaları ile alan yönetiminin sistemli ve sürdürülebilir kılınması amacıyla yeraltında gömülü kalmış arkeolojik malzemelerin, mimari elemanların ve yapı temellerinin yerlerinin belirlenmesi amacıyla arkeojeofizik çalışmalar yapılmaktadır. Arkeojeofizik çalışmalarda arazinin konumu, jeolojik ve jeomorfolojik özellikleri, toprak yapısı, yeraltı su içeriği gibi arkeolojik ve ortamın konumu ve yapısına bağlı olarak jeofizik yöntemlerden, GPR (yer radarı), manyetik,

2 http://www.kemer.gov.tr/kaymakamligimizin-kisa-bir-tarihcesi 
elektrik rezistivite, SP (doğal potansiyel), elektromanyetik, mikrogravite, sismik (kırılma ve yansıma) ölçümlerinin biri veya birkaçı seçilir. Çoklu jeofizik yöntemlerin kullanılması zaman ve ekonomik şartlar uygun olması durumunda tercih edilmelidir. 1811 yılından itibaren, farklı amaç ve doğrultularda ilerleyerek kesintilerle 2000 yılına değin süregelen Phaselis araştırmalarında bu iki temel unsurun eksikliği hayli belirgin bir görünüm kazanır.

Arkeojeofizik çalışmada hızlı ve ekonomik yeraltı bilgilerini edinmek amacıyla, genellikle, Elektrik Rezistivite Tomografi (ERT) yöntemi kullanılmaktadır. Çalışmada profil ve elektrot aralıklarının $1 \mathrm{~m}$ olması tercih edilmektedir. Elektrik rezistivite ölçümlerin veri işlem aşamaları yapıılıktan sonra iki ve üç boyutlu görüntüleri oluşturulmuştur. Elde edilen ERT profil kesitleri ve iki boyutlu kat haritalarında, toprak altında kalmıs mimari unsurlar ve yapı temellerine ait olabilecek, yüksek rezistiviteli anomali değerlerinin köşeli, kare, geometrik, dairesel ve çizgisel görünümlü geometrik formlar verip vermediği ve jeolojik ortamın fiziksel ve geometrik özelliklerinin görüntülenebilmesi izlenmektedir ${ }^{3}$.

Hellenistik Tapınak ${ }^{4}$ olarak adlandıılan çalışma alanının kuzeybatısında Phaselis Araştırma istasyonu ve kentin kuzey batı nekropolis alanı bulunmaktadır. Alanın doğo-güneydoğusu kentin limanlarına bakmaktadır. Alanın kuzeyindeki tepeden Kumluca-Antalya yolu geçmektedir. Yolun güneyinde sahile doğru iki fay ile yamaç kırık morfolojisinin denetiminde topoğrafyası gelişmiştir. Bu fayları oluşturan depremler aynı zamanda antik yerleşmeyi ciddi şekilde etkilemiş görünür.

\section{İnceleme Bölgesi Genel Jeolojisi}

Inceleme alanı ve yakın civarında Triyas-Kretase ve Kuvaterner'e ait birimler mostra vermektedir. Triyas-Kretase allokton olup, Antalya Naplarına aittir ${ }^{5}$. En çok mostra veren de Tekirova Ofiyolotik Napı'dır. Üst nap olarak kabul etmektedir. Dünit, harzburjit larzorit ve benzeri türü ultra bazik kayaçlarla gabro diyabaz, diyorit türü bazik kayaçlardan oluşmaktadır. Genel Jeoloji Haritasında bazik ve ultrabazik kayaçlar ayırtlanmıştır (Fig. 3). 1/5000 ve 1/1000 ölçekli mühendislik jeolojisi haritalarında ise Tekirova Ofiyolitik Napı (of) olarak karakterize edilmiştir. Birimin yüzey zonunda atmosferik koşullarda gelişen otohidratasyon zonu alterasyon neticesinde serpantinleşme yaygındır.

Robentson ve Woodcock (1980), Antalya Körfezi batısında araştırmalarda bulunmuşlar ve bölgeyi Beydağları Zonu, Kumluca Zonu, Gödene Zonu, Kemer Zonu, Tekirova Zonu olmak üzere beş farklı zona ayırmışlardır ${ }^{6}$.

Bölgenin, kıta kenarında oluşmuş fosil transform fay alanı olduğunu; En Üst Kretase-Alt Paleosen aralığında, genellikle Ofiyolitten türemiş çakıltaşların, doğrultu atımlı fayların fazında oluştuğunu; ayrıca Gödene Zonu olarak tanımladıkları birimdeki serpantinitlerin gerilme ile açılan çukurların altından diyapirik olarak yükseldiklerini; Tekirova Zonu'nu oluşturan ultramafiklerin ise Geç Kretase'ye ait okyanus kabuk parçası olduğunu, Robentson ve Woodcock (1980), belirtirler.

Inceleme alanında ofiyolit melanj üzerinde çakıltaşı blokları yer almakta, çakıltaşı blokları, eğimli arazide kırılarak düşmektedir.

Kuvaterner yaşlı, alüvyon birim ise (Qal) kıyı şeridindeki plaj oluşukları ise (Qp) ile karekterize edilmiştir. Alüvyonel birim içerisine, dere malzemesi de dahil edilmiş ayrıca ayırtlanmamıştır. Karasal bir oluşum olan bu birimler; inceleme alanının tamamında (\%90) izlenmektedir. Alüvyon

3 Yüksel et al. 2007; Yüksel et al. 2016; Yüksel 2017; Yüksel et al. 2017b; Avcı et al. 2016; Yıldırım et al. 2017; Yüksel Avcl 2018.

4 Daha detaylı bilgi için ayrıca bk. Arslan-Tüner Önen 2019, 426 vd.

Şenel et al. 1981, 13-43.

6 Robertson - Woodcock 1980, 125-145. 
kireçtaşı silisik kireçtaşı ve ofiyolotik bileşenlerden oluşur. Dere yataklarında 35 m'ye varan kalınlıklar sunar.

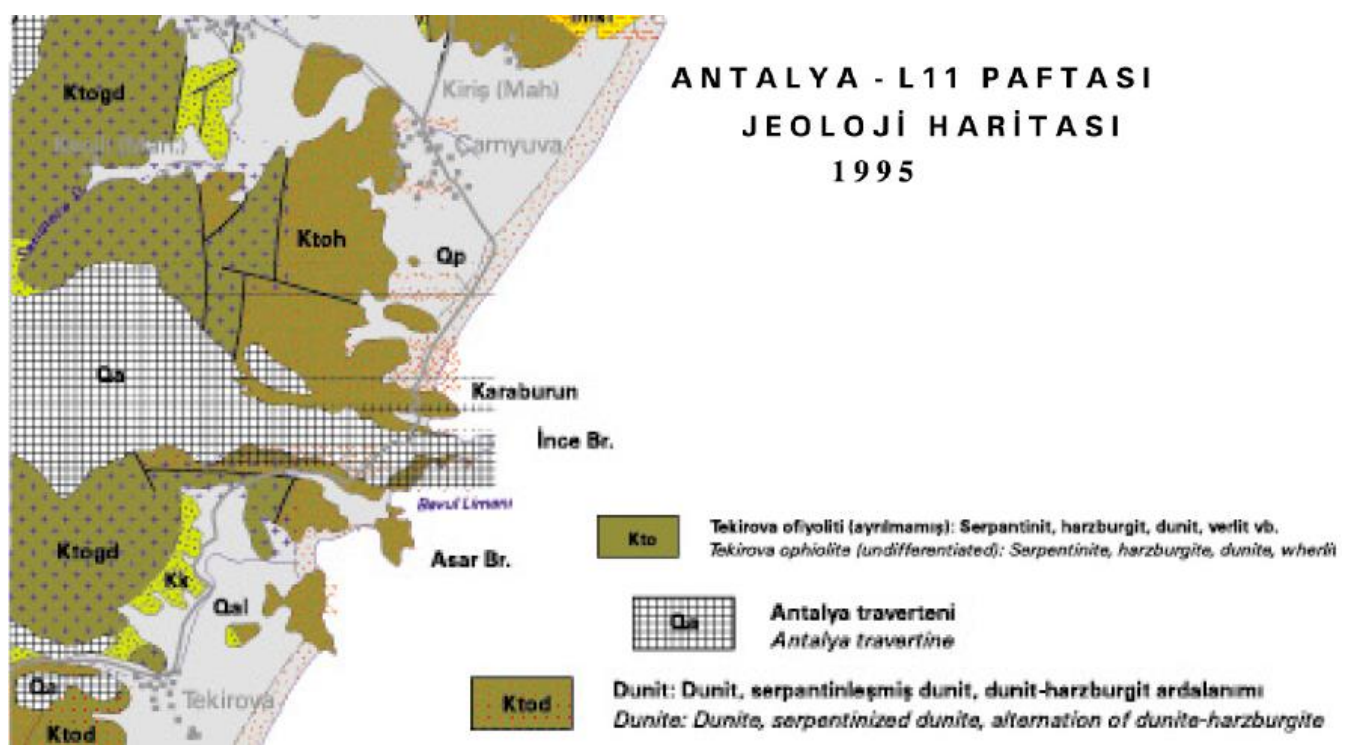

Fig. 3. Inceleme Alanı MTA Yerbilimleri Haritası (MTA 1995, Antalya L11 Paftası, Jeoloji haritası)

\section{Arkeojeofizik Jeoelektrik Değerlendirmesi}

Antalya İli, Kemer İlçesi Phaselis antik kenti, ören yerinde, tapınak olduğu düşünülen alanda, daha önce kazısı yapılmış alanda, yan yana üç ayrı lokasyonda, G-K doğrultulu, 16 profilde, $26 \mathrm{~m}$ profil uzunluğunda, her profilde $1 \mathrm{~m}$. elektrot aralıklı, çok elektrotlu ERT (Elektrik Rezistivite Tomografi) serimi yapılmıştır. Profiller arası $1 \mathrm{~m}$ olarak alınarak, yaklaşık 4-8 m. derinliğin incelenmesi hedeflenmiştir.

\section{Jeofizik Çalışmalar}

Elektrik Özdirenç (Resistivity) yöntemi olarak da bilinen doğru akım özdirenç yönteminde amaç, yer içinin jeolojik yapısını, fiziksel olarak elektrik iletkenlik özelliğinden ortamın iletken ve yalıtkanlık özelliğine göre haritalanmasıdır. Yöntem, maden, mineral, jeotermal enerji kaynağı ve petrol aramaları ile hidrojeoloji ve mühendislik jeolojisi problemlerinin çözümünde kullanıldığı gibi arkeolojide de başarıyla, tahribatsız (NDT) bir yöntem olarak, özellikle 1980'lerden itibaren, arkeolojik yapıların aranmasında da yaygın olarak kullanılmaktadır.

\section{Çok Elektrotlu Elektrik Rezistivite Tomografi Yöntemi (ERT)}

Sığ yapıların araştııımasında genellikle yatay resistivite taraması olarak adlandırılan profilleme ölçüm tekniği kullanılır. Bu teknikte; seçilen elektrot diziliminin türüne bağı olarak her bir derinlik düzeyi için yapılan ölçümlerle yeraltının görünür rezistivite yapma kesiti (pseudo-section) elde edilir. Bu tür bir ölçümün tek kanallı bir rezistivite cihazıyla yapılması oldukça büyük bir zaman alır. Oysa sığ yapıların araştııımasında hızlı, duyarlı ve kısa sürede ölçüm yapacak cihazlara gereksinim vardır. Tanımlanan özelliklere sahip olarak üretilen çok kanallı (multi-electrode) cihazlar, bu amaçlar doğrultusunda son yıllarda oldukça yaygın biçimde kullanılmaktadır (Dahlin, 2001).

Çalışmanın amacına uygun olarak elektrot dizilim türlerinden uygun olanı seçilerek veri toplama aşamasına geçilir (Fig. 4). Çok elektrotlu ölçüm ekipmanları için veri toplama şeması aşağıdadır. 
a)
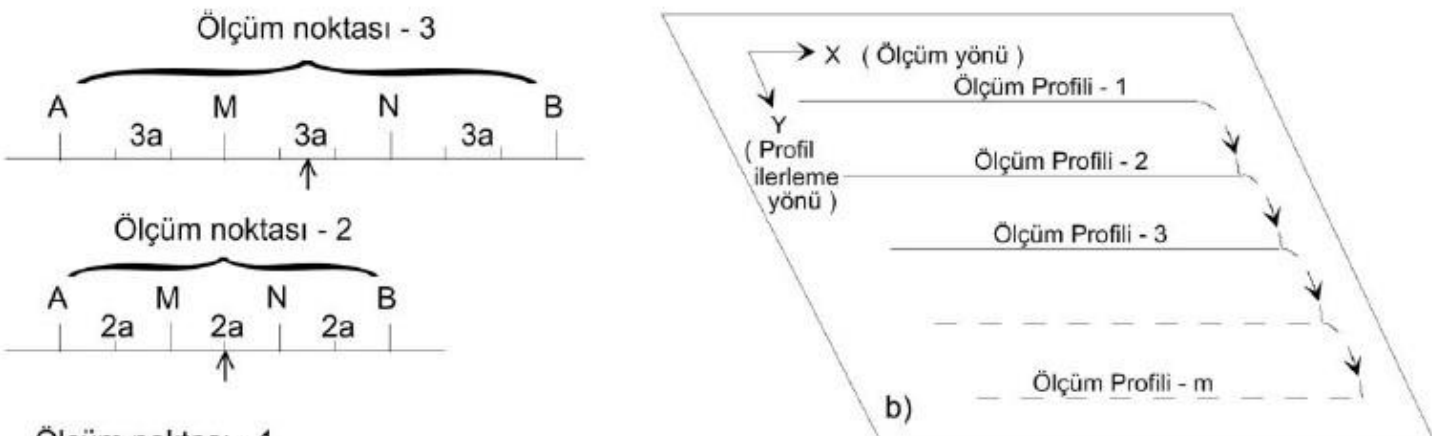

Ölçüm noktası - 1

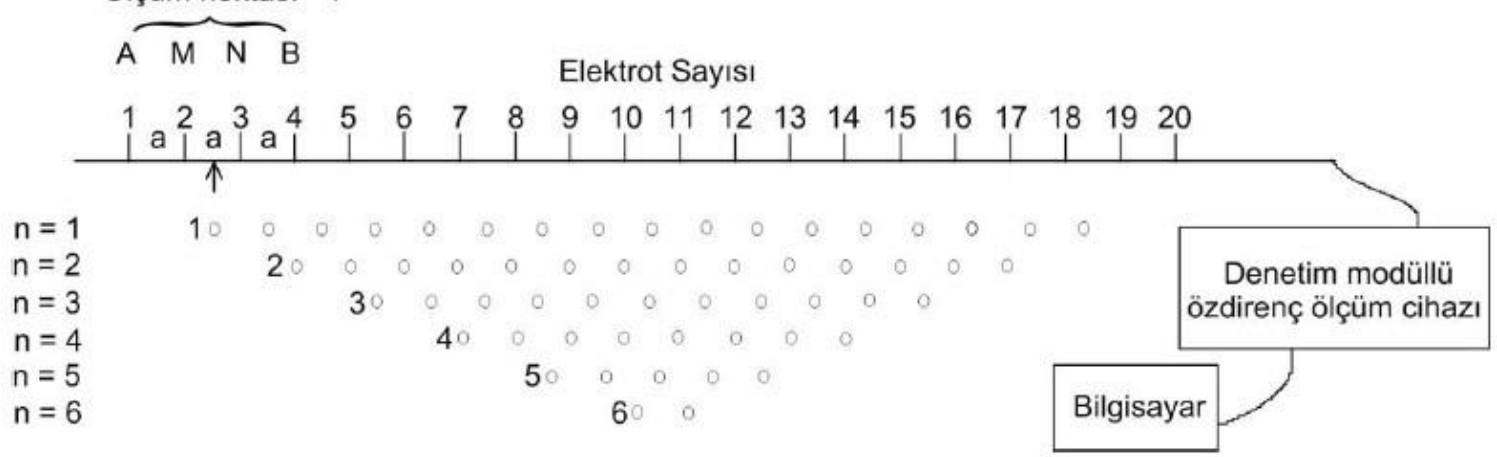

Fig. 4. 1iki-boyutlu ve b) üç-boyutlu elektrik resistivite tomografi verisinin toplanması (Griffiths ve Barker, 1993'den yeniden düzenlenerek) ${ }^{7}$

Elektrik Rezistivite Tomografi (ERT) Çalışması: Çalışma alanında Wenner dizilim türü uygulanmış, elektrot aralığı 1 m olarak belirlenmiş, 26 elektrot kullanılmış ve toplam hat uzunluğu 25 m olarak elde edilmiştir. "Arazi çalışması esnasında her bir elektrot için kot değerleri okunmuş, veri işlem aşamasında veriler çizim proğramı ile değerlendirilmiştir. Kesitler elde edilen özdirenç (ohm.m) değerlerine göre ayrımlanmış, tabaka sınırları belirlenmiş, litoloji ile ilişkilendirilmiş ve yaklaşık olarak 7-8 m derinlik incelenmiştir. Aşağıda veri işlem aşamasında elde edilen ERT ölçüsüne ait Ölçülen, Hesaplanan ve Ters çözüm model yer almaktadır.

\section{Jeofizik Arazi Çalışmaları}

Jeofizik arazi çalışmalarında ASR-G 1101-1 A model dijital ölçüm yapan, akü beslemeli doğru akım jeofizik rezistivite cihazı kullanılmıştır (Fig. 5a,b). Cihaz özdirenç, IP, yüzde etkisi, şarjabilite ve SP ölçümlerini de yapmakta, grafiğini vermektedir.

Etüt çalışmalarında Wenner dizilim (akım ve potansiyel elektrotları eşit aralıkı) tekniği uygulanılarak yürütülen arazi çalışmalarında (Fig. 6), elektrotlar arası mesafe $1 \mathrm{~m}$ olacak şekilde 8 seviyede 100 adet ölçüm alınmıştır. Elektrotları akım elektrotu ve potansiyel elektrotu olarak elektrotlar arasındaki elektonik devreler cihazla beraber otamatik olarak yapmaktadır. Jeoelektrik rezistivite yöntemi uygulanılarak etüt edilen alanda 3 ayrı lokasyonda toplam 16 adet ERT profili seçilerek ölçü alınmıştır (Fig. 7, 8, 9). Yaklaşık 7-8 m derinlik ölçülmüştür.

7 Griffiths - Barker 1993, 211-226. 

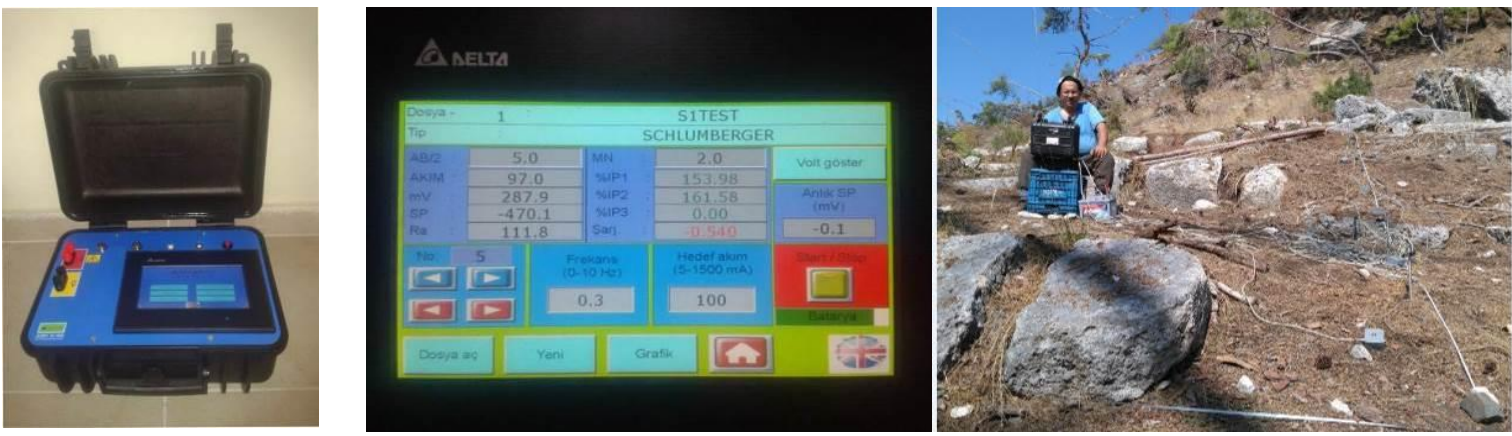

Fig. 5. a) ASRG-111-A Rezistivite ölçüm cihazı, b) cihazın kontrol

Fig. 6. Arazideki Jeofizik rezistivite ölçü alımı paneli

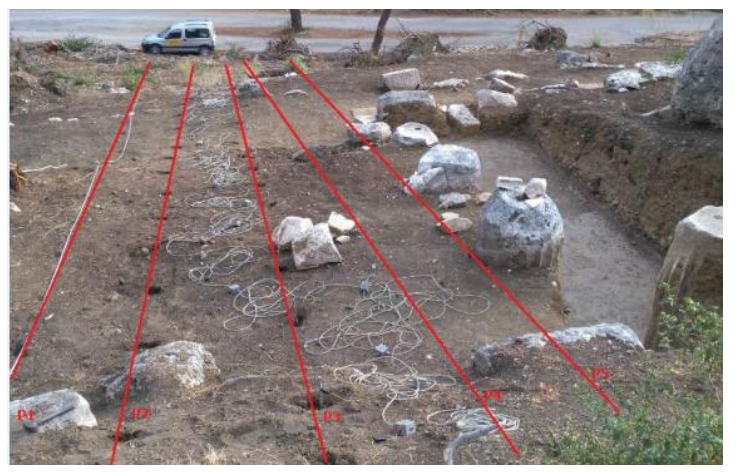

Fig. 7. Arazide (ERT) P1-P5 Profillerinin konumu (Batı)

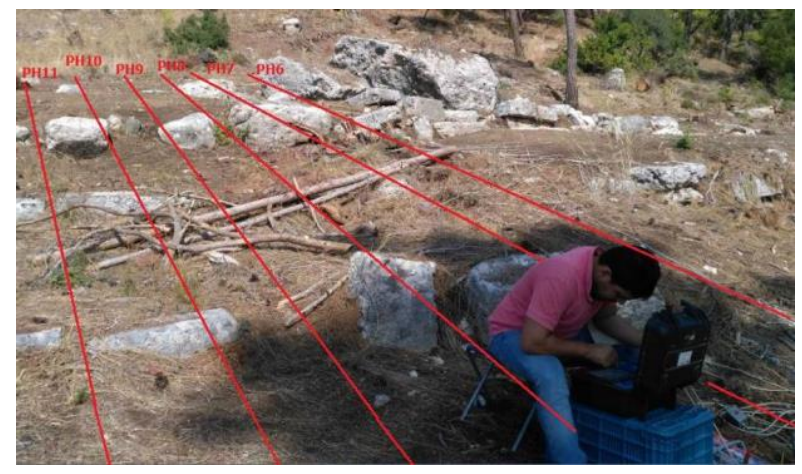

Fig. 8. Arazide (ERT) P6-P11 Profillerinin konumu (Doğu)

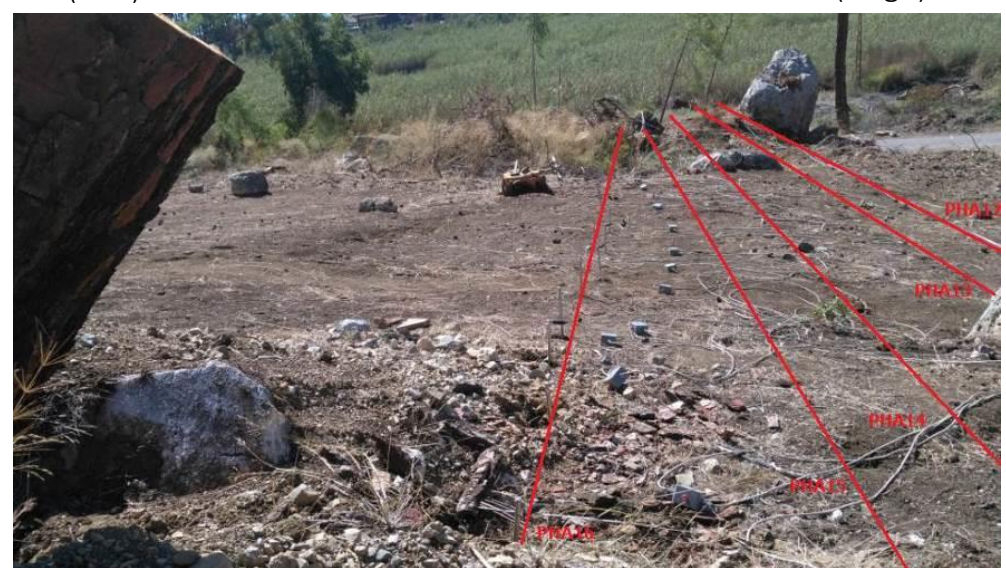

Fig. 9. Arazide (ERT) P12-P16 Profillerinin konumu (Batı)

Çok Kanallı Elektrik Rezistivite Tomoğrafi Düşey Kesiti (Ert İki Boyutlu Rezistivite Özdirenç Değişim Haritası)

Elde edilen Elektrik Tomografi (ERT) kesitine bakıldığı zaman, kesit geneli özdirenç değerlerine göre, yeşil renk ile ayrımlanan alanlar düşük özdirençli, sarı renkler ile ayrımlanan alanlar orta özdirençli ve turuncu renkler ile ayrımlanan alanlar yüksek özdirençli alanlar olarak belirlenmiştir (Şekil 11). ERT jeoelektrik kesitleri ve kat haritaları incelendiğinde eş rezistivite konturlarının temel kayanın ve temel kaya üzerinde geometrik form veren yüksek rezistiviteli anomali dağılımları görüntülenmiştir. Yer yer dairesel ve köşeli formlu yüksek genlikli anomalilerin görüntülendiği bu kesitlerde, alanda yüzeyde ve toprak altında kalmış, dağınık olan plastik mermer parçaları, sütunlar, yapı temellerine ve ana kayaya ait anomali dağılımları görüntülenmiştir (Fig. 10-17). 

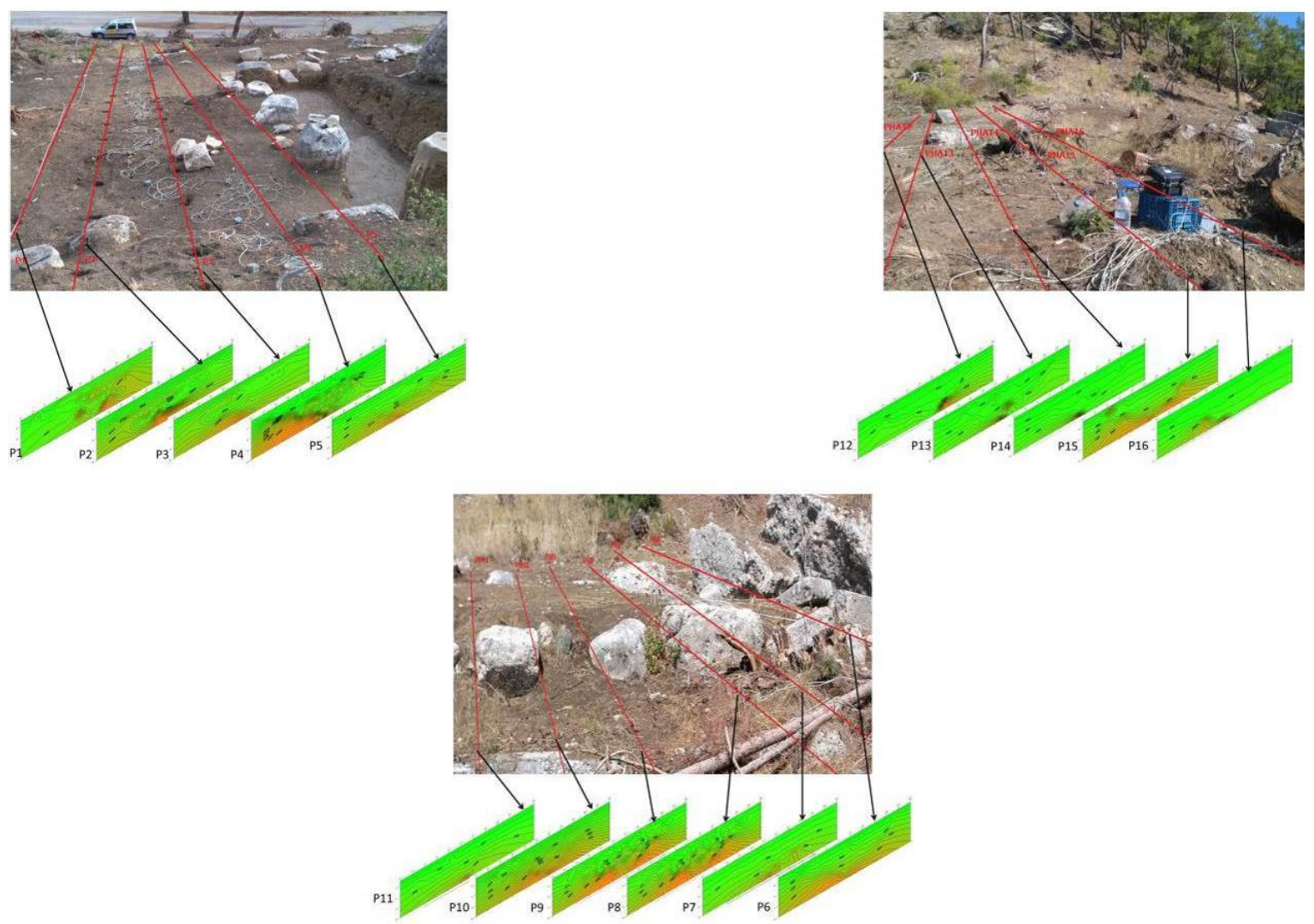

Fig. 10. Antalya İli, Kemer İlçesi Phaselis Antik Kenti ERT profil konumları ve bu jeoelektrik profillere ait anomali kesitleri

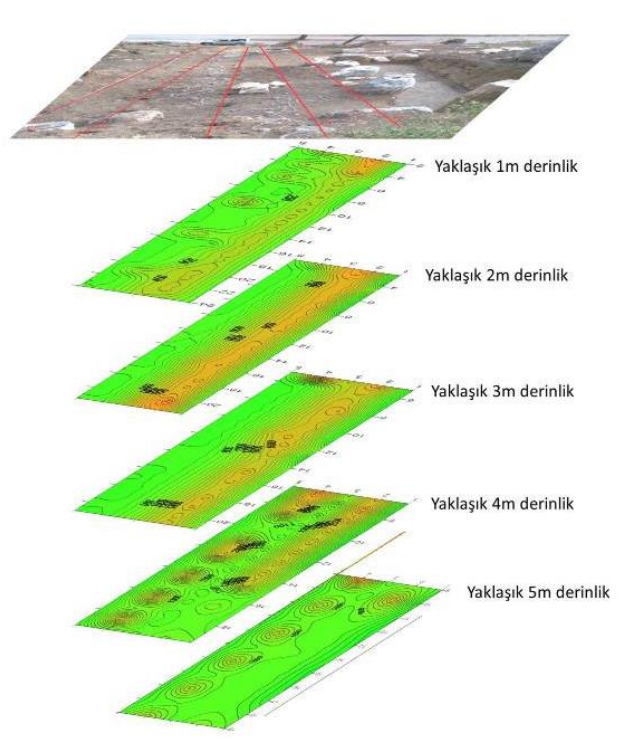

P1 - P5 PROFILLERINE AIT KAT HARITALARI
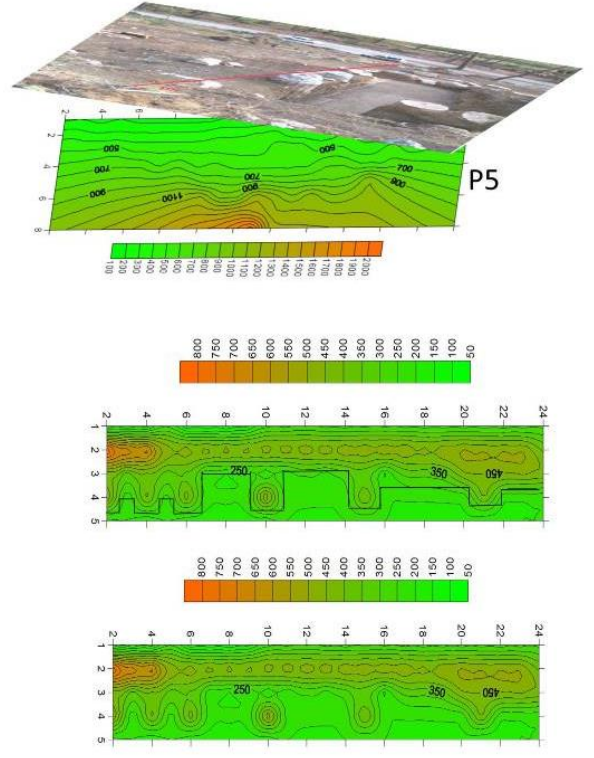

Yaklaşık $1 \mathrm{~m}$ derinlik 


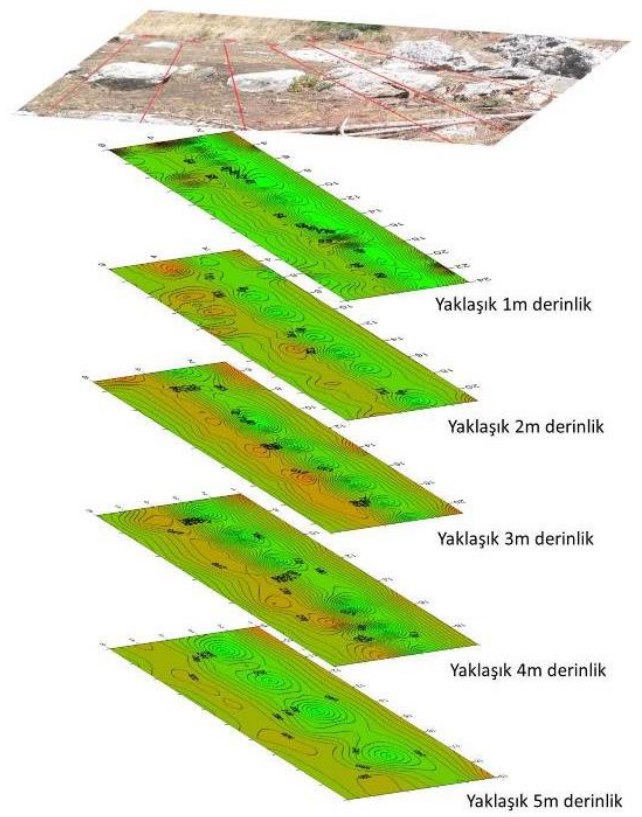

P6 - P11 PROFILLERINE AIT KAT HARITALARI

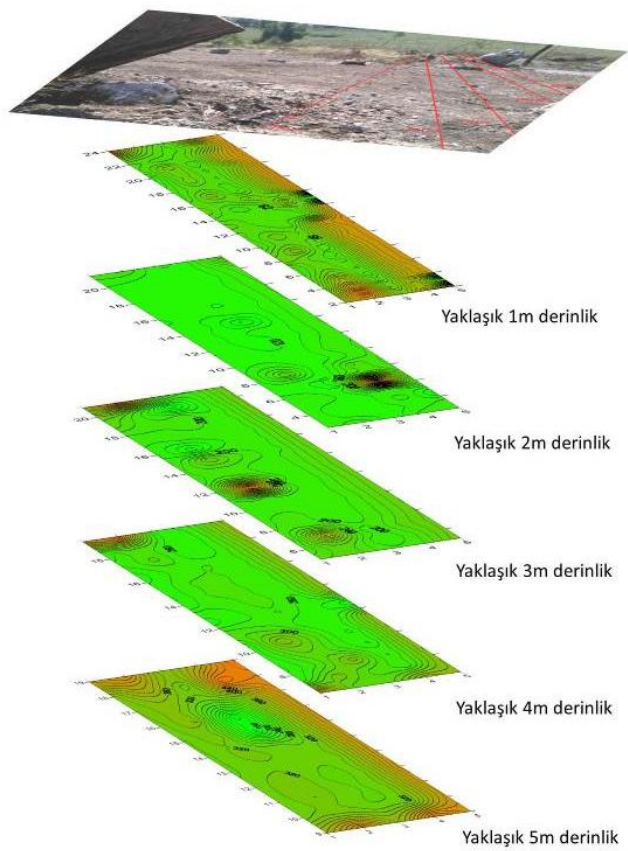

P12 - P16 PROFILLERINE AIT KAT HARITALARI

Fig. 11. Antalya İli, Kemer İlçesi Phaselis Antik Kent iki boyutlu, P1-P5; P6-P11; P12-P16 ERT profillerine ait derinlik kat haritaları ve P1-P5 profillerine ait $1 \mathrm{~m}$ derinlik için model yapılar
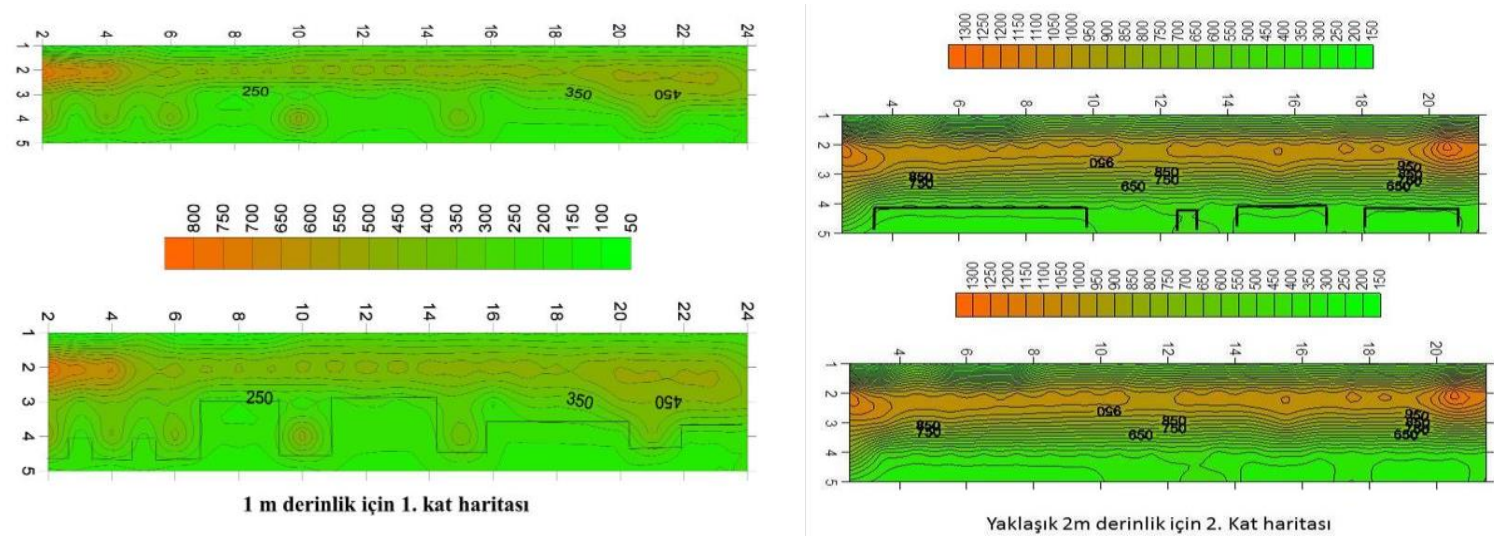

Fig. 12. Antalya İli, Kemer İlçesi Phaselis antik kent iki boyutlu kat haritaları ve olası yapı temelleri. üstte yaklaşık $1 \mathrm{~m}$ derinlik için birinci kat haritası ve olası yapı temellerinin temsili görünüşü; altta yaklaşık $2 \mathrm{~m}$ derinlik için ikinci kat haritası ve olası yapı temellerinin temsili görünüşü.
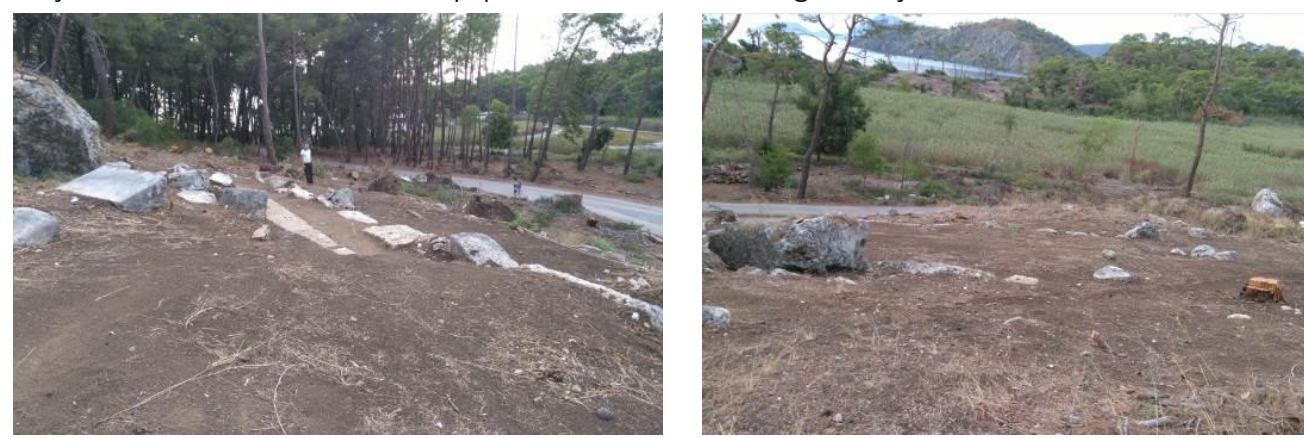

Fig. 13. Inceleme alanı genel görünümü 

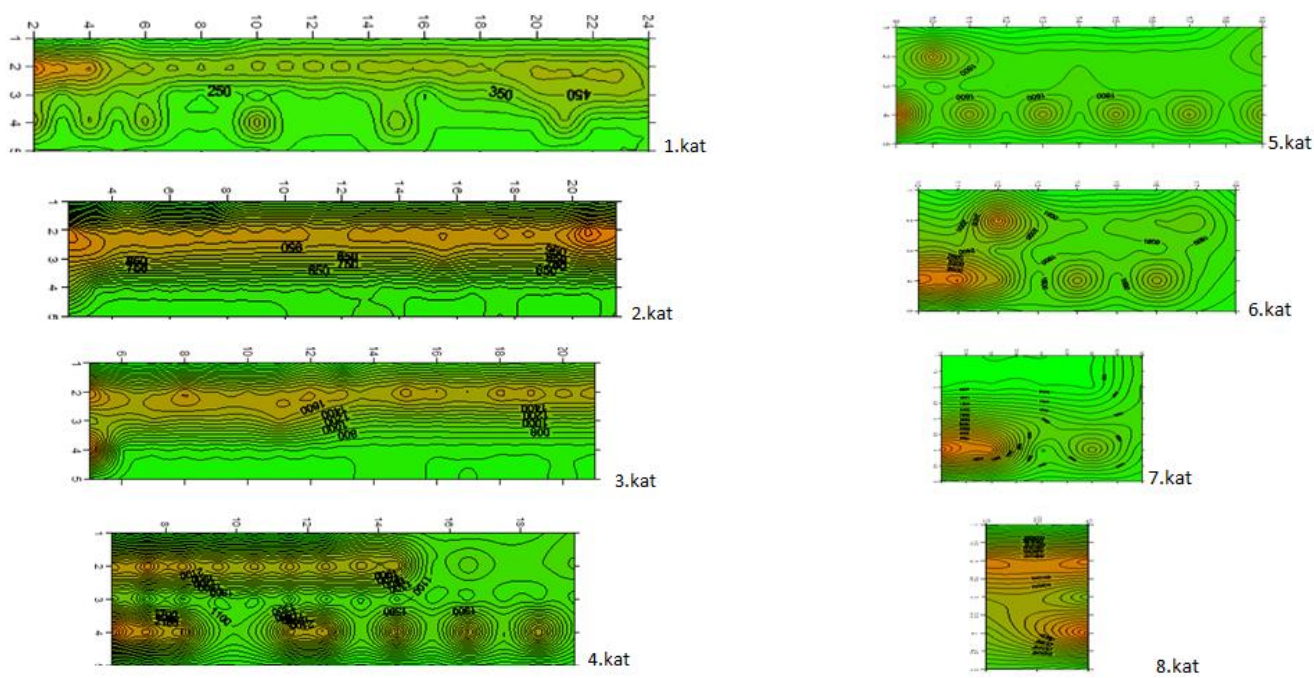

Fig. 14. Antalya İli, Kemer Illçesi Phaselis Antik Kenti P1-P5 profillerine ait ERT jeoelektrik kat anomali kesitleri
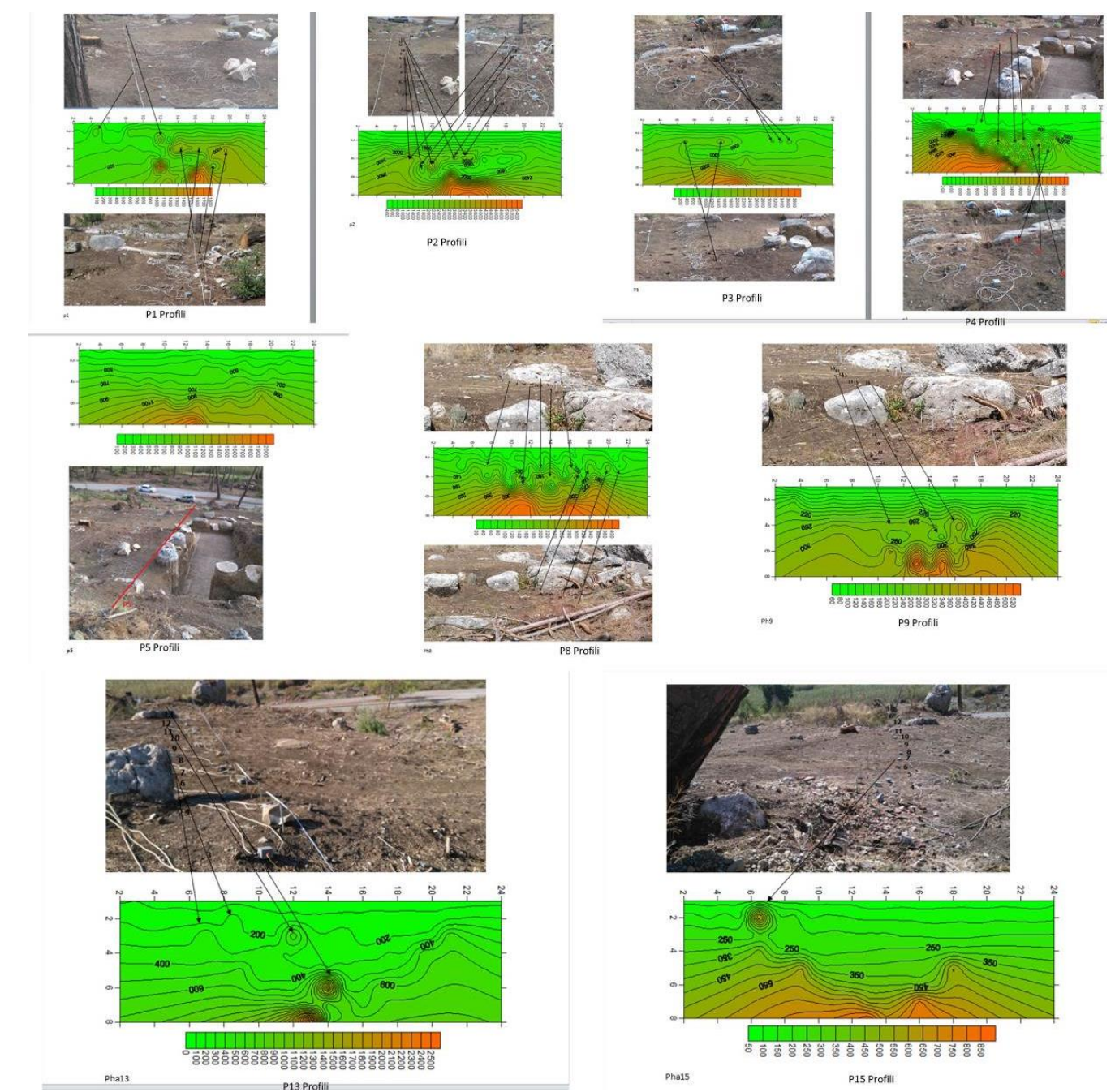

8 Profili

Fig. 15. Antalya İli, Kemer İlçesi Phaselis Antik Kenti ERT P1 -P5 profil konumları, bu profillere ait ERT jeoelektrik anomali kesitleri ve bu kesitler üzerindeki yüksek rezistiviteli lokasyonların yüzeydeki yapı elamanları ve kaya parçaları ile olası ilişkisi 
P1-P5, P6-P11 ve P12-P16 profilleri ve bu profillere ait $1 \mathrm{~m}$ aralıklı kat haritaları incelendiğinde, ölçü bölgelerinde, ana kaya ve ana kayanın üzerinde dairesel, uzunlamasına dikdörtgen ve eşit aralıklarla bir birini tekrarlayan köşeli çıkıntılar şeklinde (Fig. 10) rezistivite dağılım görüntüleri toprak altında kalmış devrilmiş sütun, sütun altı̆̆ı, yapı temel kalıntıları ve yapı yıkıntılarına atfedilebilir (Fig. 10, 11, 12, 13, 14, 15).
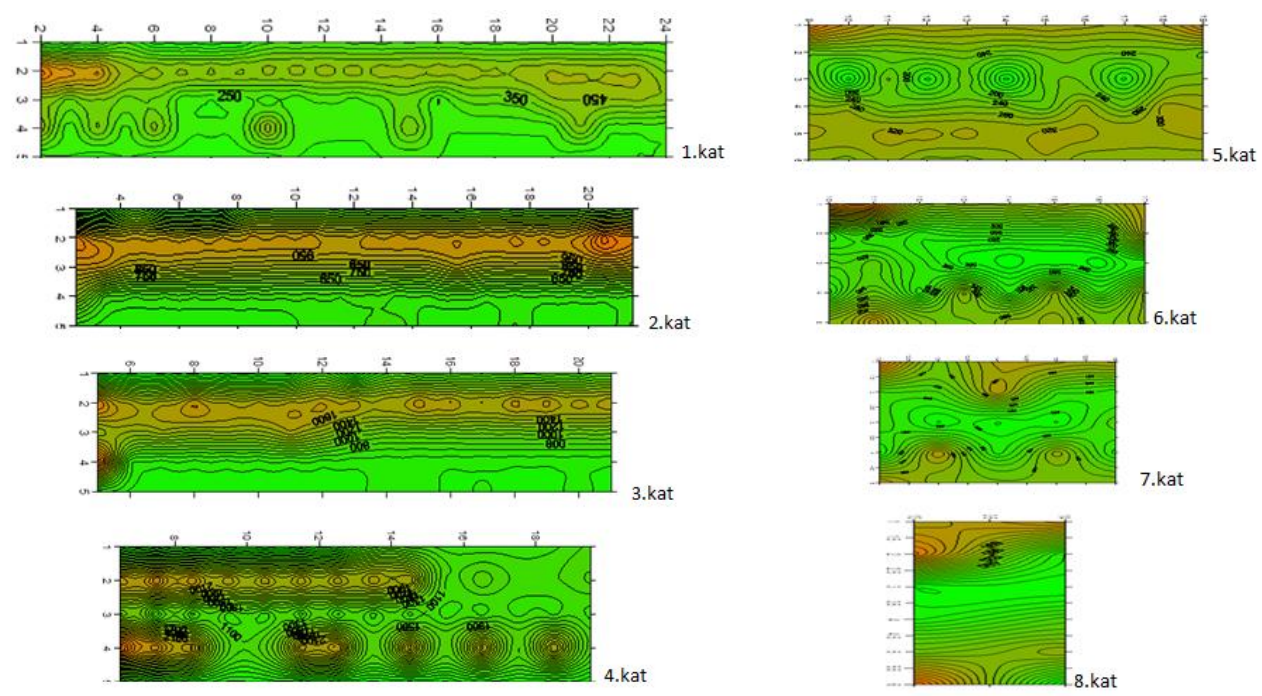

Fig. 16. Antalya Illi, Kemer İlçesi Phaselis Antik Kenti P6 - P11 profillerine ait ERT jeoelektrik kat anomali kesitleri
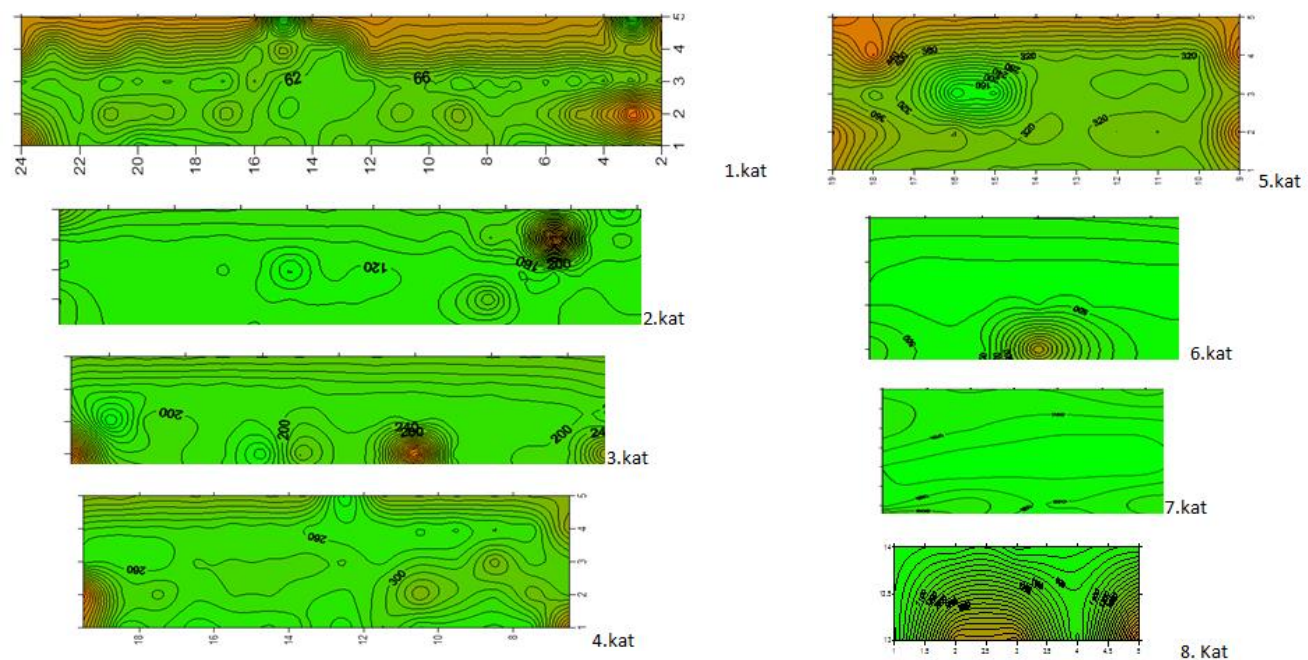

Fig. 17. Antalya Ili, Kemer Illçesi Phaselis Antik Kenti P12 - P16 profillerine ait ERT jeoelektrik kat anomali kesitleri

\section{Sonuç}

Arkeojeofizik çalışmada tapınak olduğu düşünülen alanda Elektrik Rezistivite Tomografi (ERT) yöntemi kullanılmıştır. Çalışmada $1 \mathrm{~m}$ profil aralığı ve $1 \mathrm{~m}$ elektrot aralığında ölçümler alınmıştır. Elektrik rezistivite ölçümlerin veri işlem aşamaları yapıldıktan sonra iki ve üç boyutlu görüntüleri oluşturulmuştur. ERT jeoelektrik kesitleri ve kat haritaları incelendiğinde eş rezistivite konturlarının temel kayanın ve temel kaya üzerinde geometrik form veren yüksek rezistiviteli anomali dağııımları görüntülenmiştir. P1-P5, P6-P11 ve P12-P16 profilleri ve bu profillere ait $1 \mathrm{~m}$ aralıklı kat haritalarında yer yer dairesel ve köşeli formlu yüksek genlikli anomalilerin görüntülendiği bu 
kesitlerde, alanda yüzeyde ve toprak altında kalmış, dağınık olan plastik mermer parçaları, sütunlar, yapı temellerine ve ana kayaya ait anomali dağılımları görüntülenmiştir (Fig. 16-17). Toprak altında kalmış mimari unsurlar ve yapı temellerine ait olabilecek, yüksek rezistiviteli anomali değerlerinin, geometrik form veren anomali lokasyonları, arkeolojik sondajlarla, test edilmelidir. 
Arslan - Tüner Önen 2019

Avcl et al. 2016

Boşça 2019

Griffiths - Barker 1993

MTA 29915

Robertson - Woodcock 1980

Şenel et al. 1981

Yıldırım et al. 2017

Yüksel 2017

Yüksel et al. 2007

Yüksel et al. 2016

Yüksel et al. 2017

Yüksel - Avcı 2018
Fethi Ahmet YÜKSEL - Fikret BOŞÇA

\section{BIBBLIYOGRAFYA}

M. Arslan - N. Tüner Önen, "Phaselis Kenti'nde 2019 Yılında Gerçekleştirilen Yüzey Araştırmaları ve Kazı Çalışmaları". Phaselis V (2019) 425-463.

K. Avcl, F. A. Yüksel, M. Z. Görücü, H. Aktarakçı, E. Avcl, Ş. Dönmez, "The Electric Rezistivity Tomography (ERT) Research For Oluz Hoyuk In Gozlek Willage Amasya In 2015". The $29^{\text {th }}$ Annual Symposium on the Application of Geophysics to Engineering and Environmental Problems (SAGEEP 2016), 20-24 Mart 2016. Danver (2016) 3-3.

F. Boşça, "Antalya Illi Kemer İlçesi, Phaselis Antik Kenti Tapınak Binası Arkeojeofizik Etüdü". Arz Zemin Etüt ve Mühendislik Hizmetleri Yayımlanmamış Rapor. Antalya (2019) 1-17.

D. H. Griffiths, R. D. Barker, "Two Dimensional Resistivity Imaging and Modeling in areas of Complex Geology". Journal of Applied Geophysics 29 (1993) 211-226.

MTA 1995, Antalya L 11 Paftası Jeoloji Haritası.

A. H. F. Robertson - N. H. Woodcock, "Strike-slip related sedimentation in the Antalya Complex SW Turkey". Eds P. F. Ballance - H. G. Reading, Sedimentation in Oblique-Slip Mobile Zones 4. ABD (1980) 125-145.

M. Şenel, M. Serdaroğlu, R. Kengil, M. Ünverdi, M. Z. Gözler, "Teke Torosları Güneydoğusunun Jeolojisi". MTA Dergisi 95-96 (1981) 13-43.

F. A. Yüksel, Ş. Yıldırım, K. Avcı, M. Z. Görücü, "Sinop Province, Şahintepesi Region, Bayraktepe Tumulus' Display With Electrical Resistivity Tomography". European Geosciences Union, General Assembly 2017, 2328 April 2017. Vienna (2017) 3-3.

F. A. Yüksel, "Amasya Oluz Höyük 2009-2012 Yılları Arası Arkeojeofizik Çalışmaları". Ed. Ş. Dönmez, Amasya-Oluz Höyük Kuzey-Orta Anadolu'da Bir Akhaimenid (Pers) Yerleşmesi, 2009-2013 Dönemi Çalışmaları Genel Değerlendirmeler ve Ön Sonuçlar. Amasya (2017) 363-397.

F. A. Yüksel, F. Boşça, F. Dereli, "Boyabat Kalesi Arkeojeofizik Etüdü". International Earthquake Symposium, 22-24 Ekim 2007. Kocaeli (2007) 747-747.

F. A. Yüksel, K. Avci, Ş. Dönmez, "Amasya ili, Oluz Höyük'te Elektrik Rezistivite Tomografi (ERT) Etüdü". 69. Türkiye Jeoloji Kurultayı, 11-15 Nisan 2016. Ankara (2016) 262-263.

F. A. Yüksel, K. Avci, N. Sezgin, D Kara, M. Akar, "Geophysical Prospection At Toprakhisar Höyük Altınözü, Hatay Turkey". Symposium on the Application of Geophysics to Engineering and Environmental Problems (SAGEEP) 19-23 March, 2017. Denver (2017) 297.

F. A. Yüksel, K. Avcı, "Palu Kalesinde Kültürel Mirasın Korunması ve Geleceğe Aktarılması Çalışmalarında Yeraltı Görüntülemesi". Uluslararası Palu Sempozyumu, 11-13 Ekim 2018. Elazı̆̆ 1 (2018) 273-288.

\section{Internet Erişimleri}

Google Earth, https://www.google.com.tr/intl/tr/earth/

Phaselis Antik Kenti Kazı ve Araştırmaları, http://www.phaselis.org/

Kemer Belediyesi, http://www.kemer.gov.tr/kaymakamligimizin-kisa-bir-tarihcesi 